\title{
Recurrence rates in primary spontaneous pneumothorax: a systematic review and meta-analysis
}

\author{
Steven P. Walker ${ }^{1}$, Anna C. Bibby ${ }^{1}$, Paul Halford ${ }^{1}$, Louise Stadon ${ }^{1}$, Paul White ${ }^{2}$ \\ and Nick A. Maskell ${ }^{1}$ \\ Affiliations: ${ }^{1}$ Academic Respiratory Unit, School of Clinical Sciences, University of Bristol, Bristol, UK. \\ ${ }^{2}$ Applied Statistics Group, University of West of England, Bristol, UK. \\ Correspondence: Steven P. Walker, Academic Respiratory Unit, School of Clinical Sciences, Southmead \\ Hospital, Southmead Road, Bristol, BS10 5NB, UK. E-mail: steven.walkeranbt.nhs.uk
}

@ERSpublications

PSP has a $32 \%$ recurrence rate, with almost all the risk in the first year. Smoking cessation decreases this risk four-fold. Females may be at higher risk, possibly due to sex-specific pathogenic mechanisms. http://ow.ly/Mty730kPi9z

Cite this article as: Walker SP, Bibby AC, Halford $\mathrm{P}$, et al. Recurrence rates in primary spontaneous pneumothorax: a systematic review and meta-analysis. Eur Respir J 2018; 52: 1800864 [https://doi.org/ 10.1183/13993003.00864-2018].

ABSTRACT Primary spontaneous pneumothorax (PSP) recurrence rates vary widely in the published literature, with limited data describing the factors that influence recurrence. The aims of this systematic review were to determine an estimation of PSP recurrence rates and describe risk factors for recurrence.

A systematic review was conducted of all studies reporting PSP recurrence. Electronic searches were performed to identify English language publications of randomised trials and observational studies. The population was adults with PSP, who underwent conservative management, pleural aspiration or chest drainage. The outcome of interest was recurrence. Articles were screened and data extracted from eligible studies by two reviewers.

Of 3607 identified studies, 29 were eligible for inclusion, comprising 13548 patients. Pooled 1-year and overall recurrence rates were $29.0 \%$ (95\% CI 20.9-37.0\%) and 32.1\% (95\% CI 27.0-37.2\%), respectively. Female sex was associated with increased recurrence (OR 3.03, 95\% CI 1.24-7.41), while smoking cessation was associated with a four-fold decrease in risk (OR $0.26,95 \%$ CI $0.10-0.63$ ). $I^{2}$ for random effects meta-analysis was $94 \%(\mathrm{p}<0.0001)$, reflecting high heterogeneity between studies.

This systematic review demonstrates a $32 \%$ PSP recurrence rate, with greatest risk in the first year. Female sex was associated with higher risk, suggesting possible sex-specific pathophysiology.

This article has supplementary material available from erj.ersjournals.com

This review is registered at PROSPERO with registration number CRD42018089409.

Received: May 092018 | Accepted after revision: July 012018

Copyright OERS 2018 


\section{Introduction}

Primary spontaneous pneumothorax (PSP) is a disease of young people, with an annual incidence of 7.4 per 100000 in males and 1.2 per 100000 in females [1]. Current British Thoracic Society guidelines advise that pneumothorax recurrence is an indication for surgery (whether second ipsilateral or first contralateral) [2]; however, the incidence of recurrence is unknown. PSP recurrence rates are typically cited as between $16 \%$ and $52 \%$, which makes counselling about future risk difficult and creates uncertainty regarding the optimal management [3]. If recurrence rates are genuinely as high as 50\%, an argument could be made for definitive surgical repair at an earlier stage. If the true rate is closer to the lower estimate, however, waiting for a recurrent episode before considering surgery is appropriate.

Unfortunately, there are no established factors that predict recurrence and consequently no method for risk-stratifying patients. Female sex, low body weight, smoking and height in males have all been postulated as risk factors for recurrence [4-7]. Certain radiographic features have also been suggested to confer additional risk, including bullae on computed tomography (CT) and pleural thickening on chest radiography [8-10]. Importantly, there is no consensus on which treatment offers the greatest reduction in risk of recurrence [11-14].

This study aimed to systematically review, appraise and synthesise the existing literature to determine an accurate estimate of PSP recurrence rates and to describe risk factors associated with recurrence. The primary research question was "What is the rate of recurrence of PSP in adults who have undergone medical management?". The secondary research question was "What patient factors increase recurrence risk?".

\section{Materials and methods}

Search strategy and selection criteria

A systematic review was conducted to identify English language studies, including randomised trials, nonrandomised trials and observational studies of more than 10 participants. Review articles, editorials, conference abstracts and animal or in vitro studies were excluded. The population of interest was adults $(\geqslant 18$ years of age) with PSP, although studies including adolescents aged $\geqslant 11$ years were included if they comprised $<25 \%$ of the study population or if recurrence data for adults could be extracted separately. Studies that examined patients with first occurrence or subsequent occurrence were included. Secondary spontaneous, iatrogenic and traumatic pneumothoraces were excluded, and mixed studies where PSP recurrence outcomes could not be differentiated from other types of pneumothorax (secondary spontaneous, iatrogenic or traumatic) were also excluded. Interventions and comparators included in the review were conservative management, needle aspiration, intercostal drainage (ICD) and ambulatory management. Studies that only examined surgical, thoracoscopic or pleurodesis interventions were excluded, as were mixed studies where surgical and pleurodesis outcomes could not be differentiated from nonsurgical/pleurodesis outcomes. The outcome of interest was recurrence (either ipsilateral or contralateral) at any time-point. Studies that only documented contralateral recurrence rates were not eligible.

The initial electronic search was performed on January 18, 2018 within MEDLINE (Epub Ahead of Print, In-Process \& Other Non-Indexed Citations, Ovid MEDLINE Daily and Ovid MEDLINE 1950 to January 2018) and Embase (1950 to January 2018). The full search strategy is shown in the supplementary material, and included MeSH (Medical Subject Headings) headings and key word searches of "pneumothorax", "recurrence" and "epidemiology". Two authors (S.W. and P.H.) independently screened abstracts for eligibility and excluded studies that did not meet the inclusion criteria. Discrepancies were resolved with discussion with a third author (N.A.M.). Eligible studies were obtained in full-text format and reviewed independently by two reviewers (S.P.W. and P.H.). The search was repeated on February 22, 2018 to capture recently published studies.

\section{Data analysis}

Data were extracted independently by two authors (S.P.W. and P.H.), using the data collection sheet shown in the supplementary material. Name of study, type of study, sex, age, number of PSP cases, interventions, whether PSP cases were first or recurrent episode, 1-year, 2-year and overall recurrence rates, and follow-up period were extracted from each study.

The principal summary measure was overall recurrence rate for all included studies, described using basic descriptors (mean (95\% confidence interval)). The 1-year and 2-year recurrence rates were pooled for all studies that reported these outcomes. Odd ratios for recurrence were calculated, where possible, for different interventions. Odds ratios were calculated for smokers versus nonsmokers, males versus females and body mass index $(\mathrm{BMI})>20$ versus $<20 \mathrm{~kg} \cdot \mathrm{m}^{-2}$. Hazard ratios were extracted for males versus females where available. In studies with mixed population (e.g. PSP and secondary spontaneous pneumothorax or adolescents and adults), only data pertaining to adults with PSP were extracted. If a study stated in its 
methodology that data relevant to the PICO (population, intervention, control and outcomes) criteria were collected but did not report them, the authors were contacted and asked to provide raw data.

Separate meta-analyses were conducted to examine overall recurrence rates, and 1-year and 2-year recurrence rates. All studies that reported the outcome of interest were included in the meta-analyses. Due to high anticipated heterogeneity between study populations and interventions, a random effects model was used. Heterogeneity was calculated using estimates of $I^{2}$. Pooled recurrence rates were calculated separately for clinical cohorts and epidemiological studies reporting data from the general population. Separate meta-analyses were performed for studies that reported recurrence stratified by sex, intervention, weight and smoking status to provide estimates of recurrence based on patient characteristics. Random effects models were used for all these analyses due to high anticipated heterogeneity. Univariate meta-regression was used to assess whether study-level characteristics were associated with increased reported recurrence rates. Characteristics examined were type of study (randomised control trial (RCT) versus non-RCT), year of publication (before 2000 versus after 2000), PSP type (first versus recurrent), sample size and follow-up period ( $>24$ versus $<24$ months). All analyses were conducted in Stata MP version 13.1 (StataCorp, College Station, TX, USA).

Randomised studies that met the inclusion criteria were assessed using the Cochrane risk of bias tool [15]. Bias was assessed over the following pre-specified domains: random sequence generation, concealment of allocation, blinding of participants and personnel, blinding of outcome assessment, completeness of outcome data, selective reporting, and other potential sources of bias. Nonrandomised studies that met the inclusion criteria were assessed using the Newcastle-Ottawa assessment tool over the following pre-specified domains: selection, comparability and outcome [16]. Risk of bias was assessed independently by two reviewers (S.P.W. and A.C.B.). Differences of opinion were resolved by discussion or by involvement of a third party (N.A.M.).

The review was registered prospectively on the PROSPERO database with registration number CRD42018089409.

\section{Results}

The search identified 3607 publications, of which 29 were eligible for inclusion (table 1 and figure 1). Overall pooled recurrence rate was 32.1\% (95\% CI 27.0-37.2\%) (figure 2). 12 studies documented 1-year recurrence, with a pooled recurrence rate of $29.0 \%$ (95\% CI $20.9-37.0 \%)$.

In total, 13548 patients were included in the studies, with a median (range) sample size of 79 (18-10956). 85\% were male. Study dates ranged from 1965 to 2017. Four RCTs were included: one compared needle aspiration with ICD insertion, two compared pleurodesis with standard care and one compared conservative management with surgery. 25 observational studies were included: 21 retrospective, three prospective and one population-based epidemiological study. Average follow-up time varied significantly between studies, with mean duration ranging from 3 to 96 months. A summary of included studies is provided in table 1 .

There was considerable variation in reported recurrence rates, ranging from $8 \%$ to $74 \% . I^{2}$ for the random effects meta-analysis was $94 \%(\mathrm{p}<0.0001)$. This is likely to reflect the wide variety of patient populations, methodologies and interventions studied in the included papers. Assessment of risk of bias showed a high risk of bias in at least one domain for all included studies (supplementary material).

\section{Study types}

All studies included participants drawn from clinical populations, apart from one epidemiological study that analysed population-level data, from a national health research database in Taiwan [24]. This study of over 10000 people, from a 13-year period, reported a slightly lower recurrence rate of $23.7 \%$ (95\% CI 22.9-24.5\%), when surgically managed patients were excluded, compared with the pooled estimate for clinical studies (32.6\%, 95\% CI 26.1-39.2\%). Recurrence rates were similar for randomised and nonrandomised studies (35.4\%, 95\% CI 18.7-52.1\% versus $31.7 \%$, 95\% CI 26.3-37.1\%).

\section{Factors associated with recurrence}

12 observational studies examined the association between sex and PSP recurrence $[4-6,8-10,13,17,24$, $31,33,34]$, with eight demonstrating increased recurrence rates in females $[4-6,9,10,13,16,32]$. Odd ratios could be determined from seven studies [4, 5, 9, 13, 17, 31, 33], with random effects meta-analysis demonstrating OR 3.03 (95\% CI 1.24-7.41; p=0.015) for female sex (figure 3). Four studies reported hazard ratios for sex and meta-analysis yielded an estimated HR 1.2 (95\% CI 0.83-1.67; p=0.35) associated with being female $[6,8-10]$. Two studies, which demonstrated no difference between sexes, were not included as either the odds ratio/hazard ratio could not be calculated [24] or only contralateral recurrences were examined in the sex subgroup analysis [34]. 
TABLE 1 Study characteristics

\begin{tabular}{|c|c|c|c|c|c|c|c|c|}
\hline $\begin{array}{l}\text { First author } \\
\text { [ref.] }\end{array}$ & Year & Type of study & $\begin{array}{l}\text { Primary spontaneous } \\
\text { pneumothorax } n\end{array}$ & Interventions & Excluded patients (n) & First episode & $\begin{array}{l}\text { Follow-up } \\
\text { months }\end{array}$ & $\begin{array}{l}\text { Overall } \\
\text { recurrence rate }\end{array}$ \\
\hline AL-ALAWI [17] & 2009 & Retrospective & 208 & Conservative, ICD & None & Not stated & $42^{\#}$ & 0.35 \\
\hline AL-MourgI [18] & 2015 & RCT & 22 & Conservative, surgery & Underwent surgery (19) & First & $32.4^{\#}$ & 0.41 \\
\hline Andersen [19] & 1965 & Retrospective & 138 & Conservative, ICD & $\begin{array}{l}\text { Secondary spontaneous } \\
\text { pneumothorax (48) }\end{array}$ & First & $71^{\#}$ & 0.16 \\
\hline CASALI [10] & 2013 & Retrospective & 176 & Conservative, ICD, & None & First & $58^{\#}$ & 0.46 \\
\hline С HAN [12] & 2006 & Retrospective & 89 & Needle aspiration & None & $\begin{array}{l}\text { First and } \\
\text { recurrent }\end{array}$ & 12 & 0.16 \\
\hline Chen [20] & 2008 & Retrospective & 18 & $I C D$, surgery & Underwent surgery (34) & First & $16^{\#}$ & 0.28 \\
\hline $\mathrm{CH}_{\text {Hen }}[21]$ & 2008 & Retrospective & 33 & Needle aspiration, pleurodesis & Underwent pleurodesis (31) & First & $13^{\#}$ & 0.33 \\
\hline Chen [22] & 2013 & RCT & 108 & ICD, pleurodesis & Underwent pleurodesis (106) & First & 12 & 0.49 \\
\hline GANESALINGAM [9] & 2010 & Retrospective & 100 & Conservative, ICD & None & First & $57^{\#}$ & 0.54 \\
\hline HARVEY [23] & 1994 & RCT & 73 & Needle aspiration versus ICD & None & First & 12 & 0.21 \\
\hline Huang [24] & 2017 & Epidemiological & 10956 & Conservative, ICD, surgery & Underwent surgery (8606) & First & $60-144$ & 0.24 \\
\hline KARASAKI [25] & 2014 & Retrospective & 93 & HVCD & Underwent surgery (6) & First & $12.5^{\pi}$ & 0.34 \\
\hline КІм [26] & 2014 & Retrospective & 55 & Conservative, ICD, surgery & Underwent surgery (1) & $\begin{array}{l}\text { First and } \\
\text { recurrent }\end{array}$ & Unclear & 0.16 \\
\hline KUAN [27] & 2009 & Retrospective & 48 & $\begin{array}{c}\text { Conservative, needle aspiration, } \\
\text { ICD, surgery }\end{array}$ & $\begin{array}{l}\text { Underwent surgery (13); } \\
\text { recurrent pneumothorax (21) }\end{array}$ & First & 3 & 0.08 \\
\hline LICHTER [28] & 1974 & Retrospective & 24 & Conservative, ICD, surgery & $\begin{array}{c}\text { Secondary spontaneous } \\
\text { pneumothorax (54); underwent } \\
\text { surgery (18) }\end{array}$ & First & $60-144$ & 0.08 \\
\hline LIGHт [29] & 1990 & $\mathrm{RCT}$ & 22 & ICD, pleurodesis & $\begin{array}{l}\text { Secondary spontaneous } \\
\text { pneumothorax (171); underwent } \\
\text { tetracycline pleurodesis (19) }\end{array}$ & $\begin{array}{l}\text { First and } \\
\text { recurrent }\end{array}$ & $29.1^{\#}$ & 0.32 \\
\hline $\begin{array}{l}\text { MaRTínez-Ramos } \\
\text { [30] }\end{array}$ & 2007 & Retrospective & 55 & Conservative, ICD & None & First & $30.7^{\#}$ & 0.24 \\
\hline Mehta [31] & 2016 & Retrospective & 216 & ICD & None & Not stated & $14^{\pi}$ & 0.13 \\
\hline Nishiuma [32] & 2012 & Retrospective & 66 & Needle aspiration & Failed needle aspiration (25) & $\begin{array}{l}\text { First and } \\
\text { recurrent }\end{array}$ & 12 & 0.36 \\
\hline Noн [33] & 2015 & Retrospective & 109 & Conservative, ICD, surgery & $\begin{array}{l}\leqslant 19 \text { years of age (328) and } \\
\text { underwent surgery }(76)\end{array}$ & Not stated & Unclear & 0.48 \\
\hline Noн [34] & 2015 & Retrospective & 79 & Conservative, ICD & Underwent surgery (183) & Not stated & Unclear & 0.37 \\
\hline Olesen [6] & 2016 & Prospective cohort & 257 & Conservative, ICD & None & First & $43.2^{\text {ๆ }}$ & 0.56 \\
\hline $\begin{array}{l}\text { OuAnes-Besbes } \\
\text { [13] }\end{array}$ & 2006 & Prospective & 63 & $\begin{array}{l}\text { Conservative, needle aspiration, } \\
\text { ICD, pleurodesis, surgery }\end{array}$ & $\begin{array}{l}\text { Underwent pleurodesis (16); } \\
\text { underwent surgery (1) }\end{array}$ & First & $34^{\#}$ & 0.23 \\
\hline PrimaVesi [8] & 2016 & Retrospective & 23 & Conservative, ICD, surgery & Underwent surgery (33) & First & $67^{1}$ & 0.74 \\
\hline SADIKOT $_{\text {A }}$ ] & 1997 & Retrospective & 153 & $\begin{array}{l}\text { Conservative, needle aspiration, } \\
\text { ICD }\end{array}$ & None & First & $54^{\#}$ & 0.54 \\
\hline SAYAR [35] & 2014 & Prospective & 154 & $I C D$, surgery & Underwent surgery (27) & Not stated & $30.6^{\#}$ & 0.14 \\
\hline Schramel [36] & 1996 & $\begin{array}{l}\text { Retrospective } \\
\text { case-control }\end{array}$ & 78 & Conservative, ICD, surgery & $\begin{array}{l}\text { Underwent surgery (97); no } \\
\text { follow-up (34) }\end{array}$ & $\begin{array}{l}\text { First and } \\
\text { recurrent }\end{array}$ & $96^{\#}$ & 0.39 \\
\hline TAN [5] & 2017 & Retrospective & 97 & $\begin{array}{c}\text { Conservative, needle aspiration, } \\
\text { ICD, surgery }\end{array}$ & Underwent surgery (176) & First & 39 १ & 0.56 \\
\hline TuLAY [37] & 2015 & Retrospective & 68 & $I C D$, surgery & Underwent surgery (14) & First & Unclear & 0.27 \\
\hline
\end{tabular}

RCT: randomised controlled trial; ICD: intercostal drain; HVCD: Heimlich valve chest drain. " ${ }^{\text {: }}$ mean; ${ }^{\text {ๆ }}$ median. 


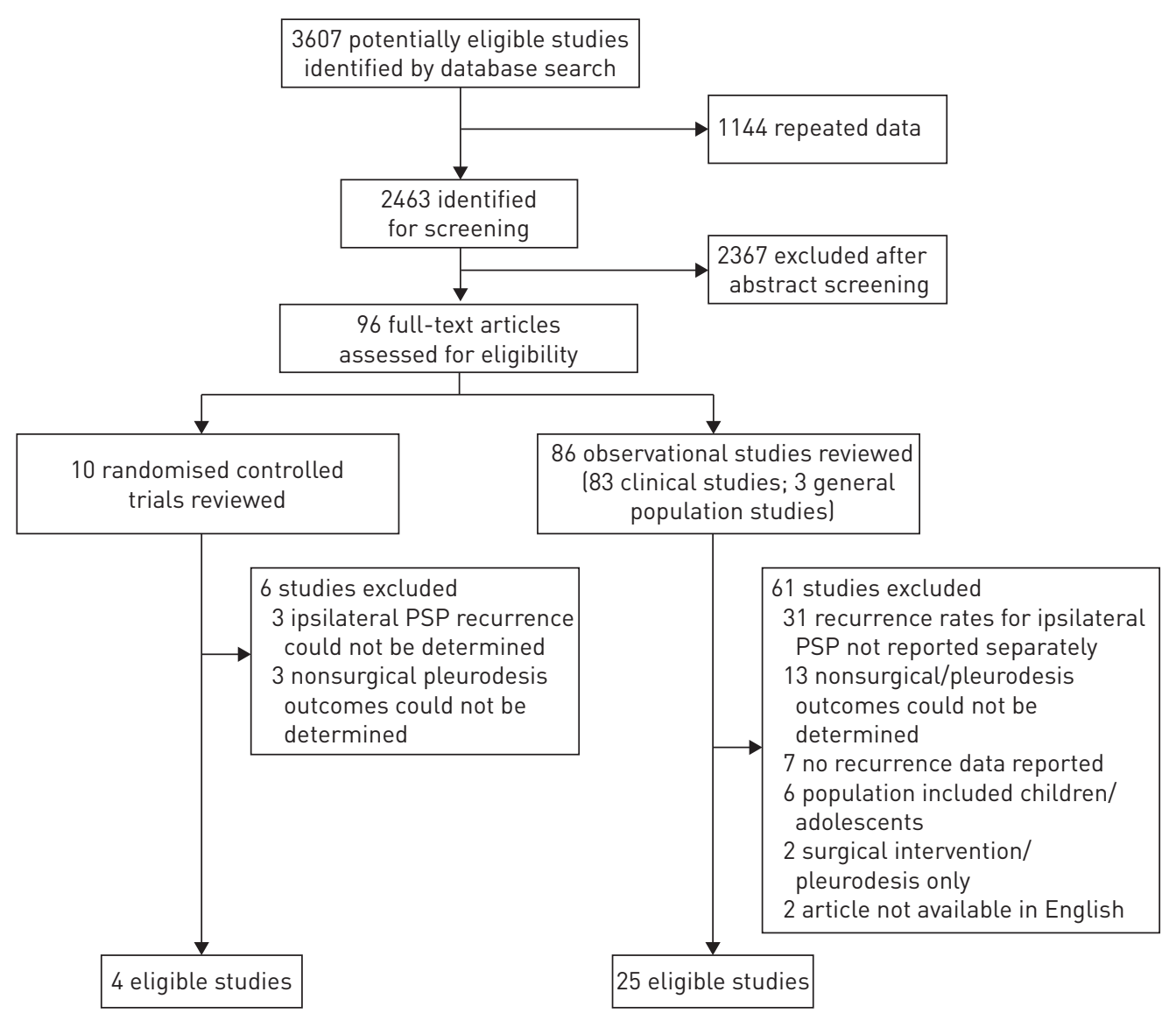

FIGURE 1 PRISMA flow diagram of study selection. PSP: primary spontaneous pneumothorax.

Several different definitions and cut-offs were used to categorise smoking habits, weight and age, and therefore meta-analysis was not possible. Five observational studies examined the relationship between current smoking and recurrence [4-6, 9, 17], with only one demonstrating a convincing association [17]. However, smoking cessation was associated with reduced recurrence in two studies with OR 0.22 (95\% CI $0.05-0.97$ ) and OR 0.28 (95\% CI 0.10-0.89), with a pooled OR 0.26 (95\% CI 0.10-0.63) [4, 17].

Eight observational studies examined BMI or weight $[4-6,8,10,17,33,34]$, with two demonstrating a significant association between low BMI/weight and recurrence [5, 6]. 13 studies examined whether age correlated with recurrence, with 10 studies finding no association $[4-6,8-10,12,13,17,26,38]$. Three studies demonstrated an increased risk with younger patients [24, 33, 34].

Four studies examined CT radiographic scoring systems, based on number, size and distribution of air-filled lesions $[8,10,13,30]$. The scores were not comparable and produced conflicting results, which were not suitable for meta-analysis. Two studies found an association between radiographic evidence of blebs and recurrence risk $[8,10]$ and two studies did not $[13,30]$. One study concluded that chest radiographic features such as pleural thickening, blebs/bullae, pleural irregularities and pleural adhesions were associated with an increased likelihood of recurrence [9].

Only one study compared recurrence in patients treated with needle aspiration versus chest drain [23] therefore precluding meta-analysis. There were no RCTs comparing medical interventions with conservative management. Six nonrandomised studies compared conservative management with either needle aspiration or ICD, with neither approach demonstrating a reduction in recurrence risk (OR 0.78 , 95\% CI 0.47-1.31; $\mathrm{p}=0.353$ ) (figure 4) $[4,6,9,24,26,33]$.

\section{Meta-regression}

Univariate meta-regression did not demonstrate any significant association between PSP recurrence and study size, publication year, eligibility criteria, type of study, PSP type (first or recurrent) or follow-up period (table 2). 


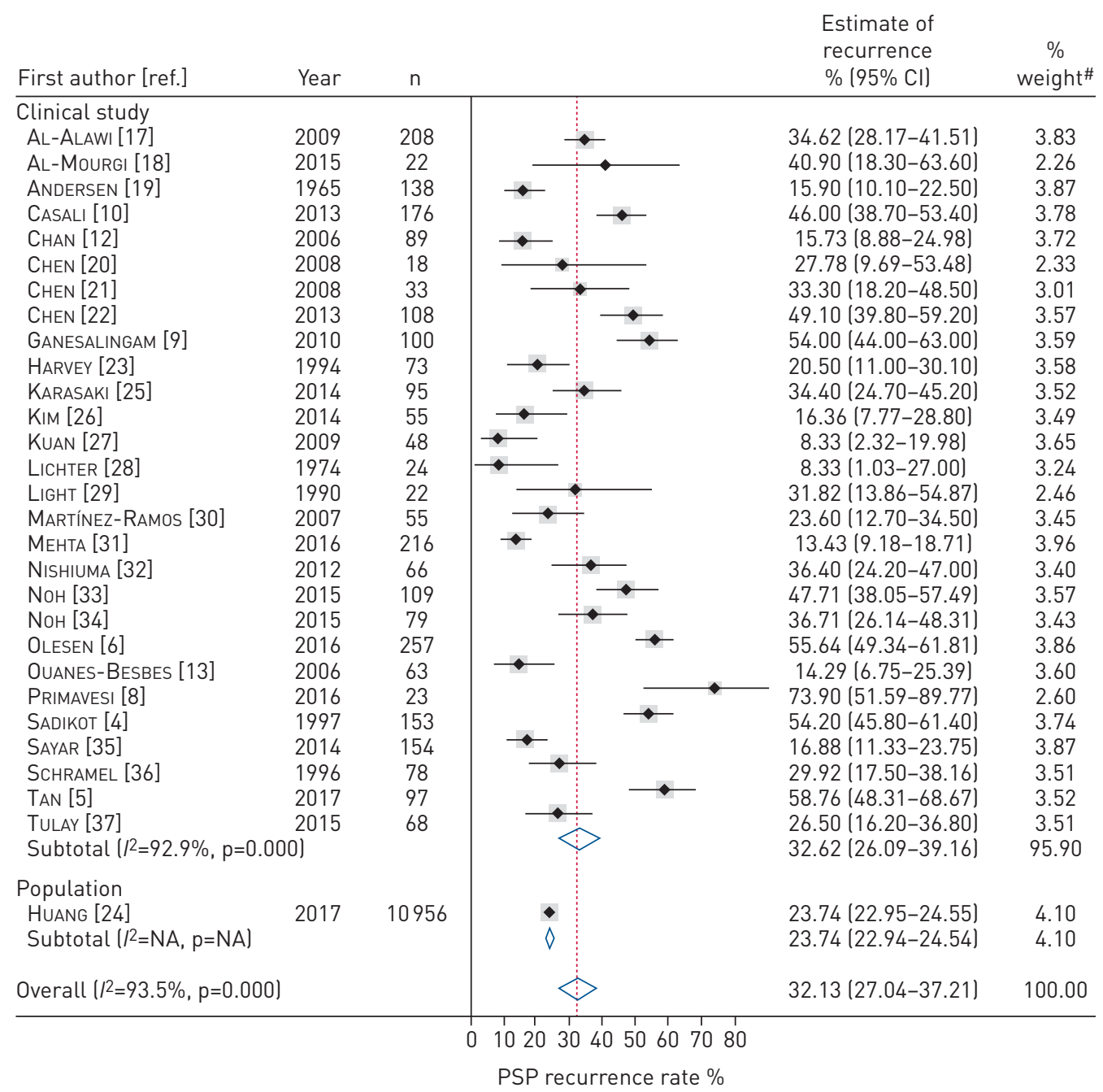

FIGURE 2 Estimate of recurrence of primary spontaneous pneumothorax (PSP) in clinical and population studies. NA: not applicable. ${ }^{\#}$ : weights are from random effects analysis.

There was considerable unexplained residual heterogeneity even after adjusting for the different study characteristics.

\section{Discussion}

This is the first study to systematically review the literature on recurrence rates in adults with PSP who have been medically managed. Meta-analysis of data from 29 studies, totalling over 13000 patients, showed that $32 \%$ of patients will experience PSP recurrence, with most occurring within the first year.

There was strong evidence that female sex was a risk factor for recurrence. This is consistent with an epidemiological study that found an increased rate of pneumothorax recurrence in female patients, particularly in the age group 31-50 years, with re-hospitalisation rates of 54\% compared with $46 \%$ in males [39]. It is recognised that a proportion of pneumothoraces in females are secondary to underlying sex-specific pathophysiology, including lymphangioleiomyomatosis and catamenial (endometriosis and nonendometriosis related) pneumothoraces. While catamenial pneumothoraces were historically thought to be a rare entity, with one early study only attributing $1 \%$ of its pneumothoraces to this condition [40], a recent retrospective study demonstrated that up to $25 \%$ of females referred to surgery for recurrent pneumothoraces had evidence of thoracic endometriosis [41]. The presence of these underlying conditions may explain the higher risk of recurrence seen in females.

Low BMI is an established risk factors for the initial development of PSP [42, 43]. While two studies demonstrated increased risk of recurrence with low weight and BMI, respectively, differing classifications precluded meta-analysis $[5,6]$. The hypothesis that PSP recurrence is linked with low body weight, either 


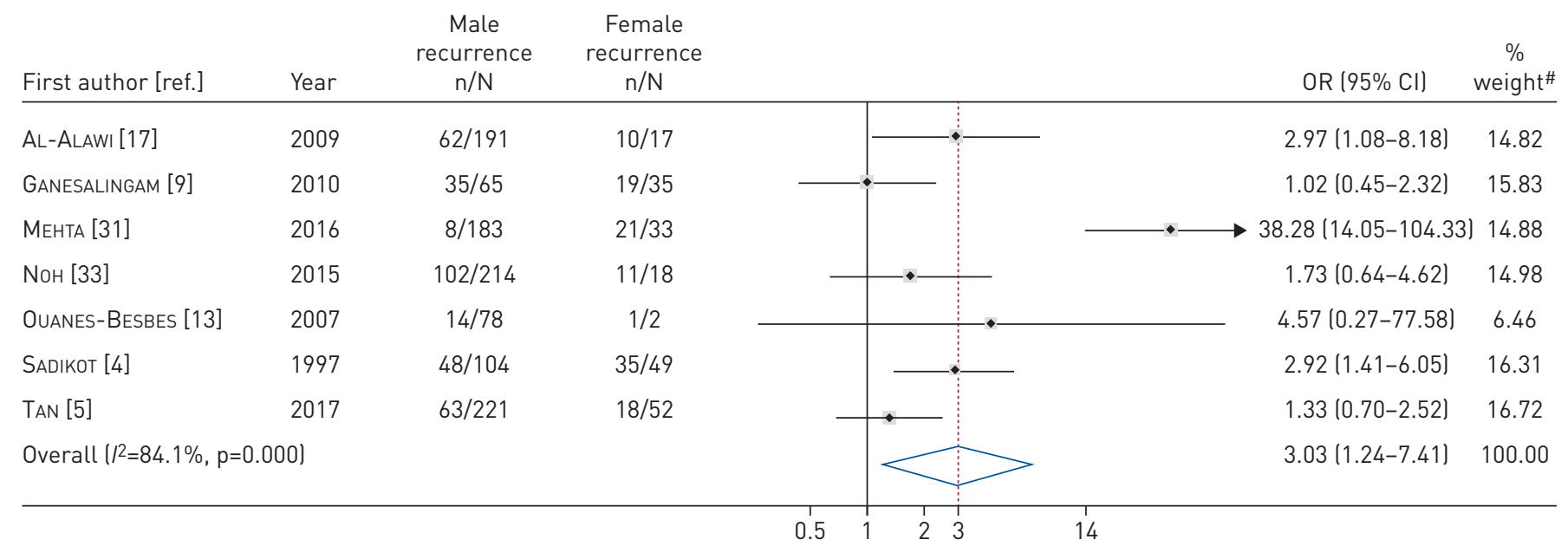

Favours male recurrence Favours female recurrence

FIGURE 3 Meta-analysis of odds ratios for primary spontaneous pneumothorax recurrence in males versus females from seven observational studies. " weights are from random effects analysis.

due to nutritional deficiencies affecting $\alpha_{1}$-antitrypsin levels or due to unbalanced physical development, was supported by two papers [5, 6, 44-46].

There is strong evidence supporting the link between smoking and developing a pneumothorax, with a clear dose-response relationship [42,47]. However, only one study in this review demonstrated an association between smoking and recurrence [17], with several studies demonstrating a trend towards increased recurrence in nonsmokers [4-6, 9, 17, 48]. It has been suggested that there is a difference in aetiology between PSP in smokers and nonsmokers, with "never-smokers" suffering from a genetic predisposition to pulmonary bullae, regardless of smoking habit. However, a more likely explanation is that the detrimental effect of smoking was obscured by the high baseline rates of cigarette smoking in the included studies and the heterogeneous classifications used to define smoking status. The fact that smoking cessation reduced the risk of PSP recurrence adds further weight to the relationship between smoking and PSP. Interestingly, this finding also suggests that smoking-related risk is reversible, at least in terms of early PSP recurrence $[4,17]$.

There were insufficient numbers of studies included to determine if the choice of medical interventions (needle aspiration versus ICD) for PSP influenced recurrence rates. A recent meta-analysis comparing RCTs of needle aspiration versus ICD insertion found no difference of recurrence at 1 year between the interventions [49]. There were no randomised data comparing conservative management to needle

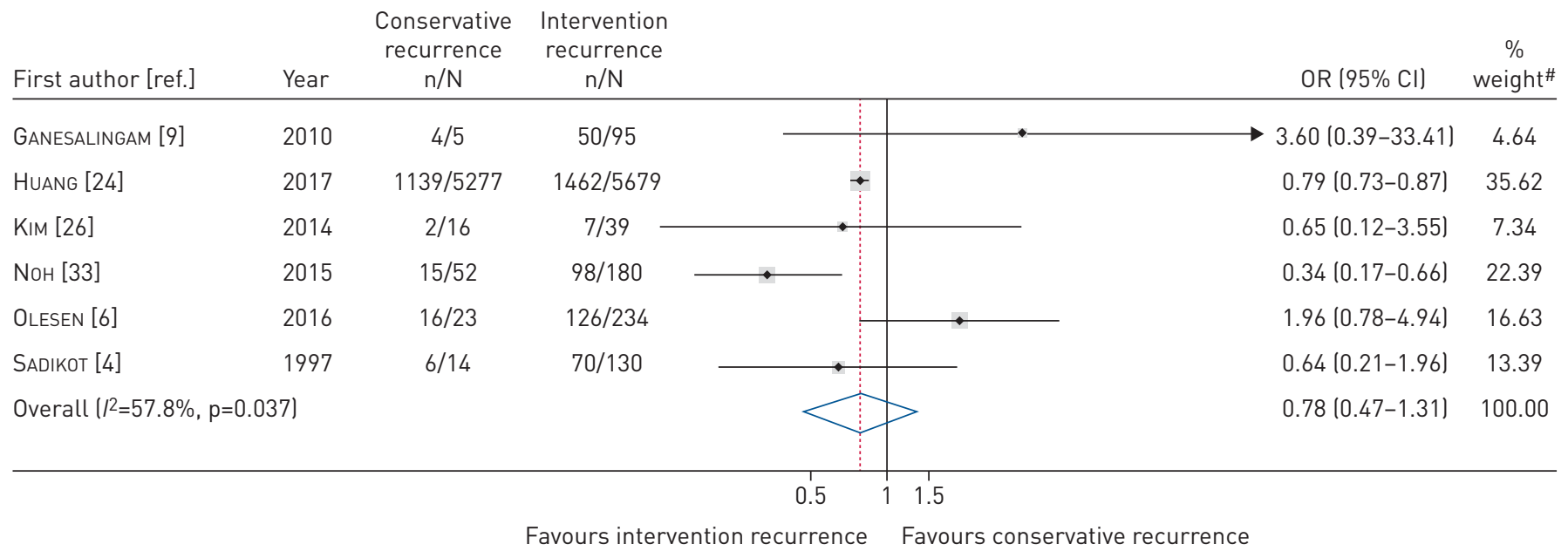

FIGURE 4 Odds ratios for recurrent pneumothorax following conservative management or intervention (needle aspiration or intercostal drainage) from six observational studies. " : weights are from random effects analysis. 


\begin{tabular}{|c|c|c|c|c|}
\hline & Studies $\mathrm{n}$ & $\begin{array}{l}\text { Pooled recurrence } \\
\text { rate } \%(95 \% \mathrm{CI})\end{array}$ & $\begin{array}{l}p \text {-value for } \\
\text { difference }\end{array}$ & Residual $I^{2} \%$ \\
\hline \multicolumn{5}{|l|}{ Study sample size $n$} \\
\hline$<100$ & 18 & $28.8(21.7-36.0)$ & 0.234 & 94.05 \\
\hline$>100$ & 11 & $37.0(28.4-46.6)$ & & \\
\hline \multicolumn{5}{|l|}{ Publication year } \\
\hline Before 2000 & 6 & $26.3(11.5-41.1)$ & 0.324 & 94.05 \\
\hline After 2000 & 23 & $33.6(27.8-39.4)$ & & \\
\hline \multicolumn{5}{|l|}{ Pneumothorax type } \\
\hline First & 18 & 35.7 (27.9-43.5) & 0.273 & 94.02 \\
\hline First and recurrent & 6 & $23.4(16.7-30.1)$ & & \\
\hline Not stated & 5 & $29.4(17.0-41.8)$ & & \\
\hline \multicolumn{5}{|c|}{ Follow-up period months } \\
\hline$<24$ & 10 & $26.5(17.7-35.2)$ & 0.303 & 93.84 \\
\hline$>24$ & 15 & $35.9(27.9-43.9)$ & & \\
\hline Not stated & 4 & $31.9(18.4-45.4)$ & & \\
\hline \multicolumn{5}{|l|}{ Type of study } \\
\hline Nonrandomised & 25 & $31.7(26.3-37.1)$ & 0.729 & 93.91 \\
\hline Randomised & 4 & $35.4(18.7-52.1)$ & & \\
\hline
\end{tabular}

aspiration or ICD, but nonrandomised data demonstrated no difference in recurrence between conservative management and intervention. It has been hypothesised that conservative management decreases the risk of recurrence, as slow re-expansion of the lung enables healing of the pleural defect [50, 51]. However, conversely, it has been postulated that chest drain insertion may inflame the pleural surfaces, promoting pleural symphysis and preventing long-term recurrence [17]. An RCT comparing standard and conservative management is currently recruiting and may offer clarification [51].

The presence of bullae on imaging has been postulated as a predictor of recurrence; however, this theory was not supported by the findings of this review. The lack of standardised radiographic scoring system may explain the conflicting results, although the hypothesis that rupture of bullae causes PSP is also debated $[13,44]$. The modified dystrophic severity score, which assessed both blebs and bullae, appeared to be the most useful radiographic scoring system; however, with a negative predictive value of $>90 \%$ but a positive predictive value of just $68 \%$, it is of greatest value as a rule-out test [10]. The dystrophic severity score has been used in one small subsequent study, but further prospective validation is required [8].

The recurrence rates reported in the included studies varied widely, likely as a result of differences in study design and population, with no single identifiable study characteristics that explained the variation.

\section{Strengths and weaknesses of this study}

This is the first systematic review of PSP recurrence rates and it provides the most reliable estimate of overall recurrence to date, based on comprehensive evaluation of existing data. Having an accurate estimate for recurrence will enable clinicians to provide better counselling for patients who have experienced their first PSP. Subgroup analysis identified factors associated with higher recurrence rates, including female sex and continued cigarette smoking. This finding will facilitate communication with patients and could be useful in guiding further treatment or investigations. For example, if a patient is thought to be at high risk of recurrence, early referral for surgery may be considered. Thus, this systematic review has clear clinical relevance and immediate potential for impact.

The methodology of this review was rigorous, with dual, independent screening of abstracts, review of papers, data extraction and assessment of study quality. Hence, we feel the result of this review is a reliable summation of the existing literature. Nonetheless, the review does have limitations. There was significant heterogeneity between the included studies, and although a random effects meta-analysis model was used, this heterogeneity may have reduced the precision of the final estimated recurrence rate. Some of this heterogeneity is likely to be a result of differing study populations and it should be acknowledged that for specific populations their true recurrence rate might appreciably differ from the estimates given. The inclusion of studies with heterogeneous populations means the resultant estimate for recurrence rate can be considered representative of the population at large, at the expense, however, of more accurate estimates for specific populations. While patients who were surgically managed or received pleurodesis were excluded from the meta-analysis on overall recurrence rates, this was not always possible in the subgroup 
analysis, which may confound these results. This review is also limited by the quality of the data in the included studies. RCT data was limited and all included studies were at high risk of bias in at least one domain. Nonrandomised observational studies are at risk of selection bias and confounding by indication, and since many of the studies were also retrospective, there was a high risk of reporting and ascertainment bias.

\section{Conclusions}

In conclusion, this is the first systemic review of factors associated with PSP recurrence, combining rates from a broad range of sources to provide a pooled overall risk. It demonstrates that $32 \%$ of patients will develop a recurrence, with most of the risk in the first year. Recurrence rates did not differ based on the initial intervention for PSP. Several factors were associated with a higher risk of recurrence, including female sex, lower BMI and radiological evidence of dystrophic lungs, while smoking cessation was associated with lower recurrence rates. There was insufficient data to consider development of a risk stratification system.

\section{Conflict of interest: None declared.}

\section{References}

1 Melton LJ 3rd, Hepper NG, Offord KP. Incidence of spontaneous pneumothorax in Olmsted County, Minnesota: 1950 to 1974. Am Rev Respir Dis 1979; 120: 1379-1382.

2 MacDuff A, Arnold A, Harvey J, et al. Management of spontaneous pneumothorax: British Thoracic Society Pleural Disease Guideline 2010. Thorax 2010; 65: Suppl. 2, ii18-ii31.

3 Schramel FM, Postmus PE, Vanderschueren RG. Current aspects of spontaneous pneumothorax. Eur Respir J 1997; 10: 1372-1379.

4 Sadikot R, Greene T, Meadows K, et al. Recurrence of primary spontaneous pneumothorax. Thorax 1997; 52: 805-809.

5 Tan J, Yang Y, Zhong J, et al. Association between BMI and recurrence of primary spontaneous pneumothorax World J Surg 2017; 41: 1274-1280.

6 Olesen WH, Lindahl-Jacobsen $\mathrm{R}$, Katballe $\mathrm{N}$, et al. Recurrent primary spontaneous pneumothorax is common following chest tube and conservative treatment. World J Surg 2016; 40: 2163-2170.

7 Guo Y, Xie C, Rodriguez RM, et al. Factors related to recurrence of spontaneous pneumothorax. Respirology 2005; 10: 378-384.

8 Primavesi F, Jager T, Meissnitzer T, et al. First episode of spontaneous pneumothorax: CT-based scoring to select patients for early surgery. World J Surg 2016; 40: 1112-1120.

9 Ganesalingam R, O'Neil RA, Shadbolt B, et al. Radiological predictors of recurrent primary spontaneous pneumothorax following non-surgical management. Heart Lung Circ 2010; 19: 606-610.

10 Casali C, Stefani A, Ligabue G, et al. Role of blebs and bullae detected by high-resolution computed tomography and recurrent spontaneous pneumothorax. Ann Thorac Surg 2013; 95: 249-255.

11 Brown SG, Ball EL, Macdonald SP, et al. Spontaneous pneumothorax; a multicentre retrospective analysis of emergency treatment, complications and outcomes. Intern Med J 2014; 44: 450-457.

12 Chan SS, Rainer TH. Primary spontaneous pneumothorax: 1-year recurrence rate after simple aspiration. Eur $J$ Emerg Med 2006; 13: 88-91.

13 Ouanes-Besbes L, Golli M, Knani J, et al. Prediction of recurrent spontaneous pneumothorax: CT scan findings versus management features. Respir Med 2007; 101: 230-236.

14 Noppen M, Alexander P, Driesen P, et al. Manual aspiration versus chest tube drainage in first episodes of primary spontaneous pneumothorax: a multicenter, prospective, randomized pilot study. Am J Respir Crit Care Med 2002; 165: 1240-1244.

15 The Cochrane Collaboration. The Cochrane Collaboration's tool for assessing risk of bias. 2011. http:// handbook-5-1.cochrane.org/chapter_8/table_8_5_a_the_cochrane_collaborations_tool_for_assessing.htm Date last accessed: July 8,2018 .

16 Wells G, Shea B, O'Connell D, et al. The Newcastle-Ottawa Scale (NOS) for Assessing the Quality of Nonrandomised Studies in Meta-analyses. Ottawa, Ottawa Hospital Research Institute, 2009.

17 Al-Alawi A, Ayed AK. Recurrence of primary spontaneous pneumothorax: rate and risk factors. Kuwait Med J 2009; 41: 288-291.

18 Al-Mourgi M, Alshehri F. Video-assisted thoracoscopic surgery for the treatment of first-time spontaneous pneumothorax versus conservative treatment. Int J Health Sci 2015; 9: 428-432.

19 Andersen B, Nielsen J. Recurrence risk in spontaneous pneumothorax. A follow-up of 178 initial occurrences in a Danish county in a ten-year period. Acta Chir Scand Suppl 1965; 356: 160.

20 Chen JS, Hsu HH, Tsai KT, et al. Salvage for unsuccessful aspiration of primary pneumothorax: thoracoscopic surgery or chest tube drainage? Ann Thorac Surg 2008; 85: 1908-1913.

21 Chen JS, Tsai KT, Hsu HH, et al. Intrapleural minocycline following simple aspiration for initial treatment of primary spontaneous pneumothorax. Respir Med 2008; 102: 1004-1010.

22 Chen JS, Chan WK, Tsai KT, et al. Simple aspiration and drainage and intrapleural minocycline pleurodesis versus simple aspiration and drainage for the initial treatment of primary spontaneous pneumothorax: an open-label, parallel-group, prospective, randomised, controlled trial. Lancet 2013; 381: 1277-1282.

23 Harvey J, Prescott RJ. Simple aspiration versus intercostal tube drainage for spontaneous pneumothorax in patients with normal lungs. BMJ 1994; 309: 1338-1339.

24 Huang YH, Chang PY, Wong KS, et al. An age-stratified longitudinal study of primary spontaneous pneumothorax. J Adolesc Health 2017; 61: 527-532.

25 Karasaki T, Shintomi S, Nomura Y, et al. Outcomes of outpatient treatment for primary spontaneous pneumothorax using a small-bore portable thoracic drainage device. Thorac Cardiovasc Surg 2014; 62: 516-520. 

high-resolution computed tomography. Thorac Cardiovasc Surg 2014; 62: 505-508.

Kuan WS, Lather KS, Mahadevan M. Primary spontaneous pneumothorax - the role of the emergency observation unit. Am J Emerg Med 2011; 29: 293-298.

28 Lichter I. Long-term follow-up of planned treatment of spontaneous pneumothorax. Thorax 1974; 29 : 32-37.

29 Light RW, O'Hara VS, Moritz TE, et al. Intrapleural tetracycline for the prevention of recurrent spontaneous pneumothorax. Results of a Department of Veterans Affairs cooperative study. J Am Med Assoc 1990; 264: 2224-2230.

30 Martínez-Ramos D, Ángel-Yepes V, Escrig-Sos J, et al. Usefulness of computed tomography in determining risk of recurrence after a first episode of primary spontaneous pneumothorax: therapeutic implications. Arch Bronconeumol 2007; 43: 304-308.

31 Mehta CK, Stanifer BP, Fore-Kosterski S, et al. Primary spontaneous pneumothorax in menstruating women has high recurrence. Ann Thorac Surg 2016; 102: 1125-1130.

32 Nishiuma T, Ohnishi H, Katsurada N, et al. Evaluation of simple aspiration therapy in the initial treatment for primary spontaneous pneumothorax. Intern Med 2012; 51: 1329-1333.

33 Noh D, Lee S, Haam SJ, et al. Recurrence of primary spontaneous pneumothorax in young adults and children. Interact Cardiovasc Thorac Surg 2015; 21: 195-199.

34 Noh D, Keum DY, Park CK. Outcomes of contralateral bullae in primary spontaneous pneumothorax. Korean Thorac Cardiovasc Surg 2015; 48: 393-397.

35 Sayar A, Kok A, Citak N, et al. Size of pneumothorax can be a new indication for surgical treatment in primary spontaneous pneumothorax: a prospective study. Ann Thorac Cardiovasc Surg 2014; 20: 192-197.

36 Schramel FM, Sutedja TG, Braber JC, et al. Cost-effectiveness of video-assisted thoracoscopic surgery versus conservative treatment for first time or recurrent spontaneous pneumothorax. Eur Respir J 1996; 9: $1821-1825$.

37 Tulay CM, Ozsoy IE. Spontaneous pneumothorax recurrence and surgery. Indian J Surg 2015; 77: Suppl. 2, 463-465.

38 Primavesi F, Aspalter M, Jager T, et al. Early surgical treatment of primary spontaneous pneumothorax reduces recurrence-rates in patients with blebs and bullae detected by computed tomography. Eur Surg 2013; 45: Suppl. 2, S73.

39 Bobbio A, Dechartres A, Bouam S, et al. Epidemiology of spontaneous pneumothorax: gender-related differences. Thorax 2015; 70: 653-658.

40 Nakamura H, Konishiike J, Sugamura A, et al. Epidemiology of spontaneous pneumothorax in women. Chest 1986; 89: 378-382.

41 Alifano M, Jablonski C, Kadiri H, et al. Catamenial and noncatamenial, endometriosis-related or nonendometriosisrelated pneumothorax referred for surgery. Am J Respir Crit Care Med 2007; 176: 1048-1053.

42 Bense L, Eklund G, Wiman L-G. Smoking and the increased risk of contracting spontaneous pneumothorax. Chest 1987; 92: 1009-1012.

43 Biffl WL, Narayanan V, Gaudiani JL, et al. The management of pneumothorax in patients with anorexia nervosa: a case report and review of the literature. Patient Saf Surg 2010; 4: 1.

44 Bar-El Y, Ross A, Kablawi A, et al. Potentially dangerous negative intrapleural pressures generated by ordinary pleural drainage systems. Chest 2001; 119: 511-514.

45 Noppen M, Baumann MH. Pathogenesis and treatment of primary spontaneous pneumothorax: an overview. Respiration 2003; 70: 431-438.

$46 \mathrm{Yu} \mathrm{L}, \mathrm{Li} \mathrm{H}$, Hou S, et al. Abnormal bone mineral density and bone turnover marker expression profiles in patients with primary spontaneous pneumothorax. J Thorac Dis 2016; 8: 1188.

47 Cheng YL, Huang TW, Lin CK, et al. The impact of smoking in primary spontaneous pneumothorax. $J$ Thorac Cardiovasc Surg 2009; 138: 192-195.

48 Lippert H, Lund O, Blegvad S, et al. Independent risk factors for cumulative recurrence rate after first spontaneous pneumothorax. Eur Respir J 1991; 4: 324-331.

49 Carson-Chahhoud KV, Wakai A, van Agteren JE, et al. Simple aspiration versus intercostal tube drainage for primary spontaneous pneumothorax in adults. Cochrane Database Syst Rev 2017; 9: CD004479.

50 Simpson G. Spontaneous pneumothorax: time for some fresh air. Intern Med J 2010; 40: 231-234.

51 Brown SG, Ball EL, Perrin K, et al. Study protocol for a randomised controlled trial of invasive versus conservative management of primary spontaneous pneumothorax. BMJ Open 2016; 6: e011826. 